\section{Mundo Revista de}

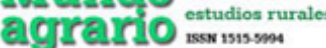

Mundo Agrario, diciembre 2018, vol. 19, n 42, e101. ISSN 1515-5994 Universidad Nacional de La Plata

Facultad de Humanidades y Ciencias de la Educación

Centro de Historia Argentina y Americana

\title{
Cien años de la Constitución mexicana y el Derecho Agrario
}

\section{Elisa Cruz Rueda}

Escuela de Gestión y Autodesarrollo Indígena, Universidad Autónoma de Chiapas, México elisacruzrueda@hotmail.com

Cita sugerida: Cruz Rueda, E.(2018). Cien años de la Constitución mexicana y el Derecho Agrario. Mundo Agrario, 19(42), e101. https://doi.org/10.24215/15155994e101

Recibido: 22 febrero 2018 - Aceptado: 10 septiembre 2018 - Publicado: 07 diciembre 2018

(c) (1)(2) Esta obra está bajo licencia Creative Commons Atribución-NoComercial-CompartirIgual 4.0 Internacional cc) ${ }_{\text {BY NC }}$ SA $h$ ttp://creativecommons.org/licenses/by-nc-sa/4.0/deed.es_AR 


\section{Cien años de la Constitución mexicana y el Derecho Agrario}

\section{One hundred years of the Mexican constitution and agrarian law}

Elisa Cruz Rueda

Escuela de Gestión y Autodesarrollo Indígena, Universidad Autónoma de Chiapas,

México

elisacruzrueda@hotmail.com

\section{Resumen:}

En el siguiente trabajo analizamos las reformas de los años 1992 y 2013 al artículo 27 de la constitución mexicana, para esto nos centrarnos en el caso de la propiedad de las tierras ocupadas y usufructuadas ancestralmente por indígenas de Aguacatenango, Chiapas. En voz de sus pobladores, la posesión data de años anteriores 1492. El caso pone en entredicho la justiciabilidad de sus derechos étnico-culturales y agrarios, y resulta ser un caso interesante de análisis de la evolución del derecho agrario en México.

Palabras Clave: Pueblos indígenas, Propiedad social, Derecho agrario, Constitucionalismo, Siglo XIX, México.

\section{Abstract:}

In the following work we analyze the reforms of 1992 and 2013 to article 27 of the Mexican constitution, for this we focus on the case of ownership of lands occupied and usufructuated ancestrally by indigenous people of Aguacatenango, Chiapas. In the voice of its settlers, possession dates back to previous years. 1492. The case calls into question the justiciability of their ethnic-cultural and agrarian rights, and turns out to be an interesting case of analysis of the evolution of agrarian law in Mexico.

KEYWORDS: Indigenous peoples, Social property, Agrarian law, Constitutionalism, 19th century, Mexico.

\section{INTRODUCCIÓN}

Este trabajo se divide en cuatro apartados: "Aguacatenango en el contexto constitucional y legal actual”; aquí apuntamos datos generales del poblado para ubicarlo como un caso de rezago agrario que coloca a sus tierras en estado vulnerable para el despojo, situación que se vuelve cada vez más común en los territorios indígenas, generalmente con vocación agrícola. En un segundo apartado "El Derecho Agrario en el caso mexicano", explicamos nuestro planteamiento sobre la situación actual de los territorios indígenas y del caso de Aguacatenango que están afectados por la transición de un Estado social a un Estado liberal; aquí abordamos grosso modo la transición entre la primera etapa del derecho agrario mexicano (1917-1991) hacia la segunda etapa (1992-2013). En el siguiente apartado nos detenemos en esta segunda etapa, "Reforma energética: la segunda contrarreforma agraria", donde explicamos la vinculación entre la vulneración de derechos que propicia esta reforma y el caso de Aguacatenango. Posteriormente expondremos el caso de Aguacatenango "De ejido a comunidad agraria: Aguacatenango, municipio de Venustiano Carranza (1922-2017)", en donde relatamos la historia de reivindicación de sus tierras a través de las acciones agrarias que existieron hasta 1992. Subrayamos que para Aguacatenango no valió en la primera etapa su condición étnico-cultural para que se le reconociera la posesión y propiedad ancestral sobre sus tierras, pese a que sus pobladores son mayoritariamente tzeltales, y, por tanto, pertenecientes al pueblo maya. Esta situación de falta de justiciabilidad la exponemos al final, en el apartado "Justiciabilidad: Ejecución de la Sentencia de Jurisdicción Voluntaria (2013-2017)" 


\section{AGUACATENANGO EN EL CONTEXTO CONSTITUCIONAL Y LEGAL ACTUAL}

El poblado y sus tierras ejidales se encuentran dentro de la circunscripción del municipio de Venustiano Carranza donde en 2008 existían dos concesiones de explotación minera (Bellinghausen 2008), que afectaban a otros núcleos agrarios indígenas. Como parte de este contexto, por lo menos tres núcleos agrarios indígenas dentro del municipio en mención tienen demandas por tierras que incluyen su titulación o legalización de la posesión, entre ellos los bienes comunales de Venustiano Carranza (Casa del Pueblo). De esta manera, existe un elemento común de ese contexto que radica en la demanda de seguridad jurídica sobre la posesión y propiedad de sus tierras de poblados indígenas, Aguacatenango es uno de esos casos. A esa falta de titulación o legalización se le conoce jurídicamente como rezago agrario histórico (artículo tercero transitorio de la Ley Agraria de 1992).

Ese es el elemento de conexión entre el caso de Aguacatenango con tierras sin titular, y lo que ahora es el Estado mexicano, indiferente por el gran rezago agrario existente en todo el país y con prisa por poner la tierra social en el mercado, sobre todo los recursos naturales posibles, como minerales, petroquímicos, turísticos, etc. existentes en esas tierras.

De esta manera, el caso que se aborda sobre reconocimiento de la propiedad social de las tierras del poblado indígena de Aguacatenango, municipio de Venustiano Carranza, descendiente del pueblo maya, es justamente un ejemplo que transita de la época del reconocimiento de la tenencia social de la tierra, por un Estado mexicano de carácter social que procuraba cumplir con el lema de "la tierra es de quien la trabaja", a una época en la que obtener tierra solo era posible pagando su precio en monedas. En este nuevo orden los mecanismos para destinarla a la utilidad pública (concepto que cambió en su definición e intención), ya no pasan por el proceso de expropiación-indemnización, sino que la vía es fast track a través del mecanismo de ocupación temporal, según se señala en la Ley de la Industria Eléctrica.

En el marco de la Constitución de 1917 el reconocimiento de la propiedad social como ejidos y comunidades agrarias empieza en los años 30 del siglo pasado (siglo XX), y que transcurre por el reconocimiento multiculturalista de derechos de los pueblos indígenas (año 2001 de acuerdo con Valladares, 2008; Burguete y McKelvey, 2013, Cruz, 2011) hasta la época actual, en que el derecho a la tierra a través del reparto agrario ha sido cancelado. En esta etapa se privilegia la privatización para garantizar los grandes capitales y las grandes inversiones, por encima de los derechos sociales, como lo es el derecho a la propiedad social de la tierra. En otras palabras, con las reformas del año 2013 los campesinos corren el riesgo de perder su tierra (sobre todo la que está bajo el régimen de propiedad social: ejidos y bienes comunales), dado el tremendo señuelo de la promesa de elevar la economía local. A esto se agrega el endeble andamiaje jurisdiccional, que reconoce derechos humanos pero que no establece mecanismos accesibles a los sujetos agrarios y son ineficientes para lograr la protección a sus derechos y, por tanto, insuficientes para una verdadera justicia que se traduzca en los hechos en mejores condiciones de vida, y que no se quede en una sentencia jurisdiccional o de un juez. A esto último denominamos justiciabilidad, concebida como los efectos de la aplicación del derecho, más allá de una sentencia jurisdiccional o de un juez (Barcenas, 2017) Este término es relevante porque en el caso de los Derechos Económicos Sociales y Culturales (DESC) donde ubicamos el derecho a la tierra, los efectos de la aplicación de la norma no son los mismos que en otros ámbitos del derecho en los que se podrían considerar "satisfechos" los derechos y las exigencias sobre el cumplimiento de los mismo solo con una sentencia, -como en el electoral, el penal o el civil-, ya que en los primeros se pone en juego la pervivencia de un pueblo, o bien, el acceso a derechos por parte de un sector social que en los hechos está en desventaja. Este escenario se complejiza mucho más porque justamente los DESC en México, aunque son reconocidos como derechos humanos no se aplican, dado que el mecanismo para su cumplimiento y el control internacional -como el Protocolo Facultativo del Pacto DESC- no se ha firmado.

Es importante precisar que la condición actual de Aguacatenango es de vulnerabilidad ante la afectación por despojo, aunque no en los niveles de embate que otros pueblos sufren sobre sus tierras, donde se 
han implementado o intentado implementar megaproyectos de inversión-extractivista, "energía limpia”, y turísticos, al cobijo de las reformas de 1992 y del 2013. El caso se encuentra dentro de los márgenes de afectación por el hecho de que las tierras que ocupa el asentamiento humano o poblado no están tituladas ni tampoco reconocidas como propiedad social o como propiedad comunal, lo que los hace vulnerables ante el despojo. Al dar seguimiento de esto pudimos constatar esta problemática, ya que las autoridades de la agencia municipal y del ejido, han tenido problemas con una persona que supuestamente les estaba tramitando el reconocimiento como municipio (pues recuperar esta categoría era el deseo de los pobladores). A cambio le pagaron y también le permitieron ocupar parte de un inmueble destinado a la escuela secundaria. Como el trámite para volverse municipio y por tanto para ser cabecera municipal no avanzaba, las autoridades del comisariado y de la agencia decidieron acudir directamente a la Secretaria General de Gobierno del Estado, donde les informaron que no existía nada tramitado al respecto, pero que además no sería posible ese reconocimiento porque Aguacatenango no cumplía con requisitos de cantidad de población y número de comunidades que se pudieran considerar en una eventual territorialidad municipal. Ante esto, las autoridades y el pueblo de Aguacatenango decidieron expulsar a esa persona, quien ahora entabló una demanda. Pero resulta que su demanda la hace sobre terrenos que justamente no están titulados ni para él ni para el poblado (aunque éste tiene la posesión ancestral) Dichos terrenos son objeto de este trabajo.

Esa situación, representada por los territorios indígenas o no, asediados o acosados por megaproyectos, es representativo de la última época del derecho agrario mexicano, donde las instituciones que tenían un papel social de defensa de los sujetos agrarios, como la Procuraduría Agraria, ahora promueven que el capital privado se imponga sobre los derechos sociales de campesinos y de indígenas -sobre todo a la tierra-, que en su mayoría están bajo la figura jurídica de tenencia de propiedad social: ejidos y bienes comunales.

Por lo anterior, el caso de Aguacatenango que se expone se encuentra en un contexto en el que la amenaza del despojo directo por invasiones (por campesinos sin tierra o acaparadores) o a través de la inversión extractivista privada se materializa cada vez más. En este sentido, y como lo hemos señalado, es destacable del caso que además de haber transcurrido más de noventa años -transitando en las distintas etapas del derecho agrario mexicano- del proceso de reconocimiento de la propiedad social sobre parte de sus tierras, hoy por hoy está inconcluso, y esto coincide justo con la época de las reformas energéticas y estructurales (año 2013) que promueven la legalización del despojo, privilegian el capital privado para la explotación de recursos naturales, y el de generación de energía sobre la actividad agrícola.

\section{EL DERECHO AGRARIO EN EL CASO MEXICANO}

El 5 de febrero de 2017 la Constitución Política de los Estados Unidos Mexicanos (CPEUM) cumplió 100 años. Sin embargo, desde su promulgación en 1917 y hasta el año 2015 ha tenido más de 600 modificaciones .

La historia agraria de México sigue atada a la historia del surgimiento de México como nación independiente, con antecedentes en las formas de organización prehispánicas y las impuestas por los invasores (Mediana, 1987). De esta manera, México Independiente surge formalmente en 1821 después de la Revolución de Independencia de 1810, con este hecho histórico se da lugar a la primera Constitución mexicana de 1824 (precedida por Sentimientos de la Nación de 1814, de José María Morelos y Pavón) y posteriormente a las de 1857 y 1917 (con la Revolución de Ayutla de 1854 y la Revolución de 1910 de por medio). Es en el artículo 27 donde se expresa uno de los elementos más importantes de México: su territorio (aéreo, aguas superficiales, someras y plataforma continental) y sus recursos naturales del suelo y subsuelo, todos propiedad de la nación mexicana.

Por considerar la tierra y el territorio como una fuente primordial de riquezas, el artículo 27 de la CPEUM, que encabeza al derecho agrario mexicano -que en su etapa previa (1917-1991) fue de carácter social-, se caracteriza fundamentalmente por reconocer la propiedad social expresada en ejidos y comunidades agrarias. Ese carácter social, en la etapa actual (1992-2013), se desdibuja en una suerte de embate en su contra, primero 
por las reformas a la CPEUM en 1992, y después en 2013 por la llamada reforma estructural-energética. Con esta última, el derecho agrario mexicano sufre una debacle, y cambia su carácter social por uno mercantilista, dado que se formaliza la liberalización del mercado de la tierra de propiedad social.

La conformación del derecho agrario mexicano como un derecho social pasó por un periodo de desarrollo muy importante, que también marcó la naturaleza del Estado mexicano de corte más social. En ese sentido, Medina Cervantes (1987) señala cinco etapas, que mencionamos grosso modo y que el autor caracteriza de la siguiente manera:

De 1915 a 1920 se promulgaron 4 leyes: Ley de 6 de enero de 1915 y en 1920.- Ley de la deuda agraria, Ley de tierras ociosas, La ley de Ejidos de 30 de Diciembre de 1920.

De 1922-1929, se promulgaron 3 leyes: Ley de tierras libres, El Reglamento Agrario del 10 de Abril de 1922. Primera Ley Reglamentaria sobre Repartición de Tierras Ejidales y Constitución de Patrimonio Parcelario Ejidal de 19 de Diciembre de 1925. Ley de Dotaciones y Restituciones de Tierras y Aguas del 23 de Abril de 1927. La Ley de Patrimonio Ejidal de 25 de Agosto de 1927.

De 1934 a 1942 se promulgaron tres Códigos Agrarios: Decreto de 23 de Diciembre de 1931, que modificaba el artículo 10 de la Ley de 6 de Enero de 1915. Decreto del 10 de Enero de 1934 que Reformó el artículo 27 Constitucional. Primer Código Agrario del 22 de marzo de 1934; Código Agrario de 23 de septiembre de 1940 y Código Agrario de los Estados Unidos Mexicanos de 1942. En 1940 se reforma el artículo 27 de la CPEUM prohibiendo concesionar el petróleo y los carburos de hidrógeno sólido, líquido o gaseoso, quedando reservada su explotación a favor de la Nación.

De 1945 a 1960 se continúa reformando el artículo 27 ampliando la propiedad de la Nación y el control de la energía eléctrica y por tanto el concepto de utilidad pública a favor del interés social. En 1945, se amplía en ese mismo artículo constitucional la propiedad y el control de la Nación sobre aguas, tanto de mares, ríos, lagos, lagunas, esteros y otros afluentes, para ser destinados a diversos usos.

De 1971-1991, Ley Federal de Reforma Agraria (1971) limitando la capacidad de los territorios (que posteriormente serían entidades federativas) para iniciar procedimientos sobre acciones agrarias (1974); se reserva a favor de la Nación el aprovechamiento de los combustibles nucleares (1975) se crean ordenamientos para regular los asentamientos humanos, se agrega la organización y explotación colectiva de los ejidos y comunidades.

A partir de lo anterior y para efectos prácticos distinguimos dos etapas: el antes y el después de 1992, es decir, de 1917 a 1991 y de 1992 a 2013.

\section{LA CONSTITUCIÓN MEXICANA ANTES DE 1992}

La Constitución de 1917 fue la primera en reconocer derechos sociales, entre ellos, agrarios, laborales y educación (reforma de 1921, de acuerdo con Gómez de Silva, 2016)

La historia mexicana ha sido marcada por una serie de eventos que se reflejan en su Constitución Política desde 1917. Entre ellos puede mencionarse la serie de invasiones e intervenciones, y, sobre todo, el despojo contra la nación mexicana provocado por naciones extranjeras, bajo el pretexto de satisfacer supuestas ofensas contra sus ciudadanos en territorio mexicano -o bien por supuestas deudas-, las cuales se proponían apropiarse de sus recursos y sobre todo de su territorio (continental, cielo, aguas, litorales marítimos y mares).

Por ello, en el artículo 27 de la CPEUM se establecieron tres principios fundamentales que nos interesa subrayar en este trabajo: propiedad originaria del territorio nacional $-y$, por tanto, el establecimiento de la propiedad social a través del reparto agrario- que definirían lo que fuera el interés público como acción del Estado para salvaguardar derechos sociales, a través de la imposición de limitaciones al ejercicio de la propiedad privada y la expropiación por utilidad pública. El principio de intervención del Estado queda plasmado en el artículo 27 y explicado por el discurso de comparecencia de Venustiano Carranza en el Congreso Constituyente (como encargado del Poder Ejecutivo el $1^{\circ}$ de diciembre de 1916), con su propuesta de reforma a la Constitución de 1857. De acuerdo con Gómez de Silva (2016, p. 99):

Al referirse en específico al tema agrario, recordó que el artículo 27 de la constitución de 1857 facultaba al gobierno para ocupar la propiedad particular, previa indemnización y por causa de utilidad pública. Al respecto, consideró que ese precepto era suficiente para que el gobierno pudiera adquirir tierras y repartirlas entre el pueblo para fundar la pequeña propiedad. 
En consecuencia, su propuesta de reforma estaba encaminada a que la declaración de utilidad fuera hecha por la autoridad administrativa, en tanto que correspondería a la autoridad judicial intervenir para fijar el justo valor de los bienes sujetos a expropiación.

A partir de la discusión de las propuestas sobre el contenido del artículo 27 se constituyeron las figuras de ejido y comunidad agraria, que serían las características centrales del Derecho Agrario que regiría hasta 1991. Además, quedó expresado de manera contundente el principio de la propiedad originaria del territorio nacional. Así, en el artículo 27 quedó plasmado que la propiedad originaria del territorio nacional corresponde a la nación mexicana, y a partir de ello se establecieron candados para evitar en lo subsecuente que pretensiones de naciones "enemigas" se apropiaran de la riqueza de la república mexicana. Para este efecto, se delega en el gobierno del Estado mexicano la rectoría de la economía y, por tanto, la protección de los bienes de la Nación, los cuales serán denominados matriz energética a efectos de este trabajo (Carmona, 2017).

De lo anterior se evidencia que existía una supremacía de la nación mexicana sobre el control de la matriz energética, pero en menos de seis años desde 1990, en el periodo presidencial de Carlos Salinas de Gortari (1988-1994), se desmanteló el andamiaje jurídico-legal o constitucional, para que el capital trasnacional vuelva por sus fueros a tener el control de dicha hegemonía, hecho que continuó en el periodo de Ernesto Zedillo (1994-2000) $)^{2}$.

Es en el gobierno de Peña Nieto que se establecen nuevas reglas para generar, almacenar, transmitir y comercializar la energía eléctrica; se impulsan al por mayor las concesiones mineras y en los últimos tiempos se privilegia la extracción de petróleo y su conducción por encima de los derechos de propietarios de la tierra, sobre todo de ejidatarios y comuneros cuyas tierras ejidales o comunales serían objeto directo de uso para permitir ese paso y explotación, hecho que hace prácticamente imposible la justiciabilidad sobre las tierras y territorios de los pueblos originarios planteada en la legislación nacional.

\section{REFORMA ENERGÉTICA: LA SEGUNDA CONTRARREFORMA AGRARIA}

Como hemos señalado, la última etapa del derecho agrario está marcada por lo que llamamos contrarreforma agraria de 1992, seguida por la reforma energética de 2013. En la primera se decretó el fin del reparto agrario y se liberalizó la compraventa de tierras sociales -ejidales y comunales- se dio libertad a las empresas (artículo 27 CPEUM fracciones IV y V) e iglesias (artículo 27 CPEUM fracciones II) de adquirir tierras y ser propietarias de las mismas; se liberalizó el marco jurídico agrario que era de marcado interés público y social al agregarse disposiciones de corte civil y mercantil. Esto estuvo aunado con la trasmutación de lo que fue la Secretaría de la Reforma Agraria (SRA), de corte centralista y proteccionista de los campesinos, a lo que ahora conocemos como la Secretaría de Desarrollo Agrario, Territorial y Urbano (SEDATU) -cabeza del sector y que, por tanto, encabeza las directrices que dependencias como la Procuraduría Agraria siguen a pies juntillas, hecho que se puede apreciar en casos en los que debió estar presente o estuvo presente-, con claras inclinaciones a impulsar el capital privado más que el interés social (Cruz, 2013).

De acuerdo con la presidencia de la república mexicana, la reforma energética se publicita por decreto del 18 de diciembre de 2013 con reformas de los artículos 25, 27 y 28 de la CPEUM. De la reforma a dichos artículos resultaron nuevas leyes como la Ley de Hidrocarburos, la Ley de Energía Geotérmica, y la Ley de la Industria Eléctrica (2014), así como la reforma a la Ley de Aguas, ${ }^{3}$ al Reglamento Interior de la SEDATU (2014), y diversas reglamentaciones y reformas a reglamentos que ya existían.

El artículo 25, modificado en 2013 en sus párrafos cuarto, sexto y octavo, marca el fin del control del Estado sobre la matriz energética, pues explícitamente se señala el impulso del capital del sector privado, no así el público ni el social (por ejemplo el de sociedades cooperativas de carácter comunitario). Por otro lado, las reformas al párrafo sexto del artículo 28 abren la posibilidad a los particulares y/o mejores postores de 
participar en la industria eléctrica (para la generación), y en materia de hidrocarburos el Estado podría hacerlo a través de empresas privadas (concesiones).

Para facilitar que las tierras con vocación agrícola - por interés comercial o por estar vinculadas a procesos sociales y culturales de comercio y subsistencia, como es el caso de los pueblos indígenas- se pongan al servicio del extractivismo, se establecen la servidumbre legal y la ocupación temporal. Su alcance jurídico es precisamente el de limitar el derecho de propiedad sobre las tierras o predios de pequeños propietarios, ejidos y comunidades agrarias. La base de estas disposiciones es civil por estar reguladas en el Código Civil Federal, y son elementos representativos de la reforma estructural-energética, porque a partir de ellas se modifica el concepto de interés público del Estado mexicano y, por tanto, de lo que ahora debe ser la utilidad pública, la cual ya no es la justicia social sino el capital.

La ocupación temporal aparece en varios ordenamientos como la Ley de Hidrocarburos y su reglamento, la Ley de Aguas y la Ley de la Industria Eléctrica. Tiene como característica central evitar el largo proceso de la expropiación-indemnización y de salvaguarda de derechos de propietarios particulares y/o sociales. De igual forma, califica anticipadamente a la actividad de la Industria Eléctrica como de interés público, general y prioritaria sobre cualquier otra actividad que tengan o hayan tenido los terrenos a afectarse/afectados, por lo que éstos tendrán que ponerse al servicio de la primera, o subordinarse a ella. De ahí la connotación de servidumbre. En otras palabras, antes de las reformas de 1992 y de 2013, el interés público del Estado mexicano era salvaguardar los derechos sociales, y fomentar la actividad agrícola.

Esta es la característica central de la contrarreforma de 1992 en materia agraria, la misma que la reforma energética vendría a coronar veintiún años después, a la cual denominamos "legalización del despojo", marcando la diferencia entre un modelo de Estado que de algún modo era social (antes de 1992) y otro denominado tecnócrata-empresarial (después de 1992) ${ }^{4}$, que busca socavar los derechos sociales, entre ellos, los agrarios. Es en el segundo modelo donde se encuentra el caso que exponemos en este trabajo, y que radica fundamentalmente en el reconocimiento formal de las tierras que ocupan el poblado o asentamiento humano y parte de las tierras laboradas mancomunadamente.

\section{Aguacatenango, municipio de Venustiano Carranza}

Para reconstruir parte del proceso histórico de Aguacatenango nos basamos en su historia oral, en la Resolución Presidencial (Res. Pres.), por la cual se le dotaron y ampliaron tierras y, en su última etapa, en el expediente en trámite de Jurisdicción Voluntaria en el Tribunal Unitario Agrario del Distrito 03. De igual forma, citamos algunos párrafos de documentos que se encuentran en el archivo del Comisariado Ejidal de Aguacatenango.

La reivindicación de la tierra por parte de este poblado ha transitado por las distintas etapas del derecho agrario mexicano, hasta llegar a la última época que denominamos de "la segunda contra reforma agraria", que marca un hito en los conceptos de utilidad pública e interés público.

La localidad de Aguacatenango se localiza en el municipio de Venustiano Carranza en la Región IV "De los Llanos" (Figura 3) en el estado de Chiapas (Figura 2). En 2010 como último año INEGI (2018) contaba con una población de 3413 habitantes, de los cuales 1670 eran hombres y 1743 eran mujeres, y su índice de fecundidad era de 3,45 hijos por cada mujer. Del total de la población, el 0,35\% proviene fuera del Estado de Chiapas, un $23,91 \%$ de su población es analfabeta.

Se encuentra a 1740 metros de latitud. El grado de escolaridad es de 3.18 (3.98 en hombres y 2.43 en mujeres). Es una pequeña comunidad tzeltal que es conocida por ser productora de blusas bordadas y artesanías de barro. La población en su mayoría se dedica a la agricultura básicamente de subsistencia, dado que los productos de esta actividad son casi en su totalidad para consumo propio. En 2017, en un taller sobre cambio climático las autoridades expresaban que su mayor problema es el agua porque en los últimos 10 años las lluvias escasean en tiempo y cantidad, y el sistema de agua potable depende de un depósito ubicado en terrenos del poblado de Amatenango. 
FIGURA 2

Chiapas en México

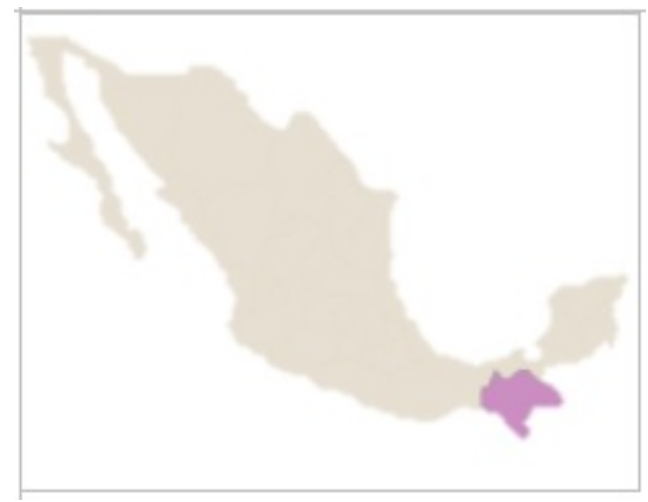

FIGURA 3

Región IV De los Llanos

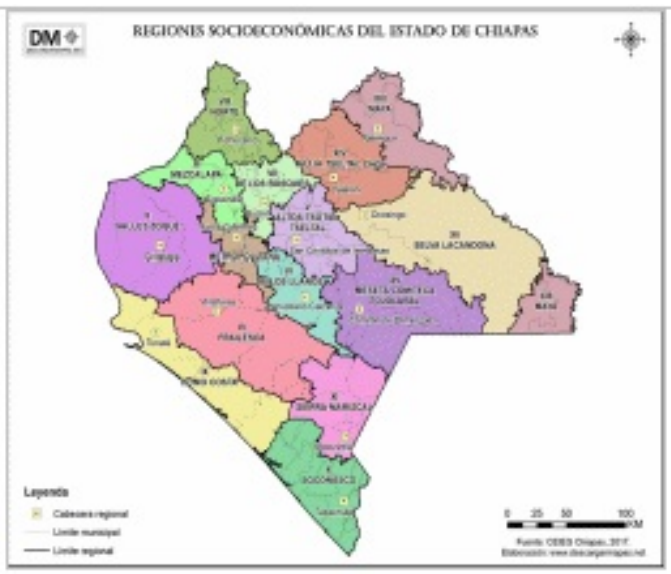

Antes de pasar a la cronología de hechos que marcaron la titulación de tierras y la actual situación del poblado consideramos importante citar el trabajo de Perezgrovas (2007, p. 77) -dada su actualidad-. El mismo al describir el poblado plantea:

El pueblo de Aguacatenango en su conjunto parece una estampa de tiempos pasados, con sus calles de tierra, gente que se desplaza siempre a pie y su plazuela amplia y coronada en su centro por un sencillo quiosco.

La iglesia ubicada en el costado oriental de la plaza, nos lleva a épocas incluso anteriores con su pequeño atrio almenado que presenta un nivel más alto, sus gruesos muros de piedra de tres metros de anchura[...]

Sobre el sistema de cargos el mismo autor agrega:

En Aguacatenango coexisten dos estructuras de autoridad: una que podría llamarse 'municipal' basada en un sistema de cargos, y la otra que corresponde al ejido. La primera tiene mayor jerarquía y está constituida por 16 personas, de las cuales 8 son funcionarios mayores que portan bastón de mando, es decir, que rigen la vida de la comunidad, establecen las cuotas para las fiestas, y se encargan de dirimir las controversias. [Perezgorvas 2007, p. 80]

\section{DE EJIDO A COMUNIDAD AGRARIA: AGUACATENANGO, MUNICIPIO DE VENUSTIANO CARRANZA} (1922-2017)

Cronología de Acciones Agrarias: De ejido a comunidad agraria (Padrón Histórico Nacional Agrario (PHINA) del Registro Agrario Nacional (RAN) PHINA-RAN) 
En este apartado expondremos a grandes rasgos el transitar de 96 años de reivindicación de los derechos agrarios de Aguacatenango, que queda enmarcado exactamente dentro del periodo del centenario de la CPEUM.

Con los antecedentes señalados más adelante, los pobladores han insistido en reivindicar la posesión ancestral de sus tierras, sobre todo sobre la base de documentos guardados en el archivo del Comisariado, los cuales, contrastados con trabajos arqueológicos, plantean de manera contundente que el pueblo de Aguacatenango tiene posesión ancestral sobre sus tierras, anterior a la época colonial.

De esta manera, García-Bárcena (1982), a partir de trabajos de reconocimiento y excavación en la Cuenca de Aguacatenango durante los años 1978 y 1979, dio cuenta de sitios arqueológicos

...que en su mayoría aparecen en superficie como concentraciones de lítica y cerámica que ocupan áreas pequeñas y carecen de montículos habitacionales o ceremoniales; la densidad de artefactos es basa. Estos sitios probablemente correspondan a casas aisladas, hechas de materiales perecederos, repartidas en un patrón de asentamiento disperso... (García B., 1982, p. 14).

Y más aún:

Aguacatenango X, cuya localización coincide con la del poblado actual; en los alrededores aparece material arqueológico en abundancia, que incluye numerosas navajas prismáticas de obsidiana (...) la presencia de este material indica que Aguacateango estuvo ocupado desde antes de la Conquista española, y también que ya entonces fue la principal población de la cuenca... (García B., 1982, p. 14).

Lo anterior se constituye como antecedente histórico de la ocupación sobre las tierras que no le han titulado a este poblado, y que, como lo afirman sus pobladores en la historia oral, se remonta a los años anteriores a la invasión española, entre los años 1492 y 1521, y posteriormente en el México independiente en sus varias etapas y periodos de reforma agraria. A pesar de este transcurrir del tiempo y a que la historia agraria de México priorizaba los derechos de los campesinos, en 2017 -en plena reforma energética- todavía está en trámite la titulación formal de las tierras que ocupa el asentamiento humano del poblado, ya que las tierras de cultivo están ya tituladas por dotación y ampliación.

Otro indicio de la posesión y derecho de propiedad del poblado de Aguacatenango es una transcripción a máquina de un documento del año 1761 en el que se asienta que Don Carlos Antonio de Velasco compró el ingenio Buena Esperanza, alias El Puerto, y que luego fue escriturado a nombre de su esposa doña Santos María de Velasco y Flores. En los papeles del reverendo padre fray Tomás Prageda consta que el 9 de julio de 1734 las justicias de Aguacatenango le entregaron a su anterior propietaria la cantidad de 230 pesos por el predio que ya se encontraba en su posesión. El predio se terminó de pagar en 1761, cuando se entregaron otros 230 pesos ante el escribano público y real don Antonio Francisco Durán de Acheyta. Se compraba así El Puerto por un total de $\$ 460$ pesos.

Pese a lo anterior, en otro documento del mismo archivo consultado se señala que, en el año 1842, el agrimensor Francisco de Paula Rovelo se apersonó en el "rancho" El Puerto a cumplir la comisión encomendada por el subprefecto de la Villa de San Barolomé de Los Llanos (hoy Venustiano Carranza) para medir el ejido de Aguacatenango. Dicha medición había sido solicitada al juez de primera instancia, don Jose Demetrio León, para ver si el terreno de El Puerto era propiedad de Aguacatenango o era terreno nacional. El juez falló a favor de los terrenos nacionales. Sin embargo, en la actualidad no existen registros de que ese predio esté catalogado como terreno nacional. Y el documento continúa narrando que maliciosamente, el agrimensor de Paula y Rovelo dijo que "los indios habían pedido que querían su ejido en dos porciones una en El Puerto [Buena Esperanza] y otra en la circunferencia del pueblo [Aguacatenango]".

Esto en parte explica que actualmente Aguacatenango tenga tres polígonos: 1 de dotación y 2 de ampliación, y que las instituciones del gobierno federal hayan dejando fuera la titulación del predio que se señaló indebidamente como terreno nacional, donde está el asentamiento humano del poblado de Aguacatenango. 
Actualmente las autoridades de Aguacatenango señalan que el agrimensor de esa época fue malicioso al haber dictaminado que el predio El Puerto era terreno nacional, cuando ya había sido una hacienda (ingenio Buena Esperanza, citado arriba) y cuando ya había sido comprado por el pueblo de Aguacatenango en 1761.

De esta manera y dado que el poblado de Aguacatenango no contaba con Títulos Primordiales, le fueron dotadas tierras como ejido en 1941 y posteriormente una ampliación en 1994. Sin embargo, el espacio que ocupa el poblado o asentamiento humano no ha sido legalmente reconocido (Figura 4). Esto lo explicaremos a continuación en una narración cronológica de hechos.

En el marco histórico previo a 1992 la comunidad de Aguacatenango, Municipio de Venustiano Carranza, inicia la lucha por la titulación de sus tierras. Sus autoridades agrarias y municipales reportan que:

....al momento de la invasión europea sobre nuestras tierras y la posterior instalación del régimen colonial, el actual territorio del estado libre y soberano de Chiapas pasó a formar parte de la Capitanía de Guatemala y por ende nuestros ancestros, que ya habitaban estas tierras, sin haber podido obtener de la dicha Capitanía de Guatemala o por cualquier otra autoridad colonial los Títulos Primordiales, como si, los obtuvieron otros pueblos originarios. O por lo menos no los conocimos, dada la separación al momento de la Independencia de todos los territorios ocupados por la Corona Española, del actual territorio chiapaneco y adherirse a la naciente República Mexicana, por lo que todos los archivos habidos durante la existencia de la Capitanía de Guatemala, y que correspondían a territorio chiapaneco, quedaron en la República de Guatemala (expediente TUA/547/2013 $)^{5}$.

Es de destacarse que, aunado a lo anterior y ya en la época del México independiente, las instituciones agrarias nacidas de la Revolución de 1910 no consideraron la condición de pueblo indígena, poseedor de tierras y con un territorio. También se destaca en la solicitud en el expediente TUA/547/2013 del pueblo de Aguacatenango, que en su momento eran municipio libre pero que luego perdió esa condición, y quedó como Agencia municipal de lo que actualmente se conoce como el Municipio de Venustiano Carranza, antes San Bartolomé de los Llanos.

Dotación de Ejido (1922-1946)

Otro dato que destaca en el expediente TUA/547/2013 es que, con fecha 22 diciembre de 1922, el poblado solicitó tierras, y se instauró el expediente en la Comisión Agraria Mixta el 2 de febrero de 1923, y es hasta el 13 de noviembre de 1940 que se emite la Resolución Presidencial publicada en el Diario Oficial de la Federación el 17 de junio de 1941, dotando al poblado de la cantidad de 1,995-00-00 hectáreas, en dos polígonos. La Resolución Presidencial se ejecutó el $1^{\circ}$ de diciembre de 1946.

\section{Ampliación de tierras (1951-1994)}

Y se continúa señalando en el mismo expediente que el 31 de enero de 1951, por Resolución de la Comisión Agraria Mixta (CAM), se le negó la ampliación, con el argumento de que "no estábamos aprovechando las tierras que nos habían sido dotadas en 1940" (escrito de demanda de Jurisdicción Voluntaria expediente TUA/547/13). Fue hasta 1954 que los pobladores recuerdan que el C. Ingeniero Camilo Quintero, comisionado del Departamento Agrario, convocó a Asamblea General del poblado de Aguacatenango, en donde se le cuestionó porque no habían sido tomadas en cuenta en la Resolución Presidencial de dotación, las tierras que ocupaba el asentamiento humano del poblado y que mantenía en explotación mancomunada. A esto el Comisionado respondió que era necesario que el poblado nombrara un Comité Particular Ejecutivo para que realizara los trámites para la titulación de dichas tierras, por lo que en esa asamblea general fueron nombrados los CC. Pedro Pérez Juárez y Agustín Espinoza Hernández, como presidente y suplente respectivamente, y, según ese ingeniero con dicha acta se iniciaría el trámite correspondiente para la titulación de sus tierras comunales. Sin embargo "Pasaron los años, idas y vueltas a la Ciudad de Tuxtla Gutiérrez y a la Ciudad de México, por parte del Comité Particular Ejecutivo y nunca supieron del número de expediente para la titulación de dichas tierras mancomunadas".

El 20 de mayo de 1960, vecinos y campesinos de Aguacatenango, Municipio de Venustiano Carranza, nuevamente solicitan ampliación de tierras. Con ello, el 19 de enero de 1962, se instauró el expediente en la Comisión Agraria Mixta (CAM), con lo que se continuó el trámite correspondiente. 


\section{La ampliación en rezago agrario (1994)}

Así transcurrió sin más noticias hasta que llegó la contrarreforma agraria de 1992, y, tal como lo establecen los artículos transitorios del artículo 27 constitucional reformado, la solicitud de ampliación fue turnada al recién creado Tribunal Superior Agrario, para que este resolviera.

Para el 16 de marzo de 1994, el Tribunal Superior Agrario resuelve el Juicio Agrario 2041-A de ampliación otorgando la cantidad de 1145-98-22.7 hectáreas. Esto se ejecuta el 31 de mayo de 1994, pero que en realidad fueron entregadas 1129-76-84, ya que las mediciones iniciales no correspondieron a los trabajos técnicos informativos realizados por la CAM en su momento. Tampoco en esta acción agraria se consideró el reconocimiento de las tierras que ocupaba el poblado, además de otras laborables.

Época del PROCEDE y las tierras de Asentamiento Humano y tierras laboradas mancomunadamente sin reconocimiento legal desde 1922 (2004-2012)

Ya en el presente siglo, a principios del año 2004, personal de la Procuraduría Agraria se presentó a una asamblea general en el ejido para informar sobre el Programa de Certificación de Derechos Ejidales (PROCEDE) (figura 4 y 4a ). Al término de su exposición los pobladores le presentaron la situación de su posesión ancestral sobre las tierras mancomunadas y, a pesar de haber solicitado su titulación dentro del procedimiento de dotación, así como en el de ampliación, no hubo respuesta de parte de la Secretaria de la Reforma Agraria.

La representación de la Procuraduría Agraria (PA), después de escuchar esta problemática, les dijo que dentro del Programa PROCEDE se podrían regularizar las tierras que mantenían en posesión de forma mancomunada. Por tal motivo, accedieron a entrar al programa PROCEDE. Sin embargo, el 20 de diciembre de 2004, fecha de la asamblea de delimitación, destino y asignación de tierras, la PA no cumplió su promesa, pues vieron que solo fueron tomadas en cuenta la dotación y ampliación del ejido, y quedaron fuera las tierras mancomunadas y del asentamiento humano. La PA argumentó que "esas son tierras nacionales".

\section{FIGURA 4}

Terrenos de Aguacatenango. El polígono más pequeño es el que falta de titular y es donde está el asentamiento humano o poblado

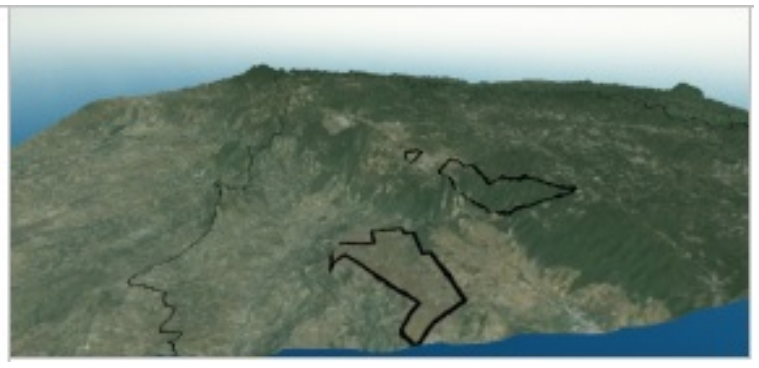

Fuente: figura tomada de google Earth

FIGURA 4A

Tierras faltantes de titulación de propiedad social a Aguacatenango

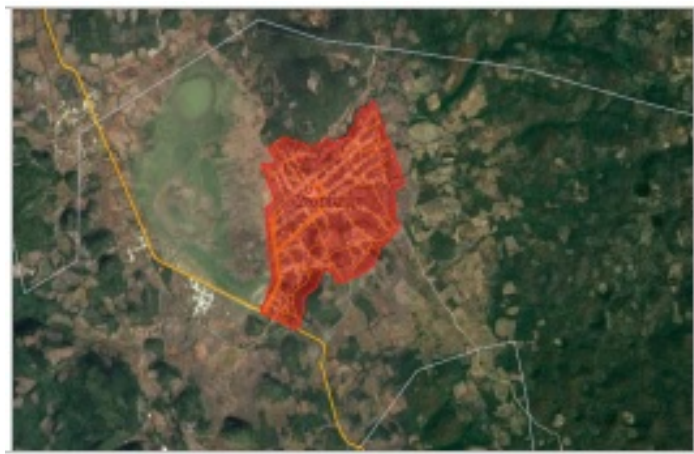


En la demanda instaurada en el Tribunal Agrario del Distrito 03 (TUA/547/2013) los representantes de Aguacatenango señalan que, para el año 2010, el poblado buscó la delimitación (medición) gratuita de las tierras faltantes de titulación. Fue el Ing. Rigoberto Sánchez González quien realizó el levantamiento topográfico de las tierras que consideraban de ancestral posesión mancomunada. Quedaron debidamente delimitadas con sus colindantes, quienes de acuerdo con palabras de los pobladores y ejidatarios de Aguacatenango reconocen -y conocen de generación en generación- que la superficie de esas tierras mancomunadas suma un total de 1447-96-46.25 hectáreas.

Finalmente la Asamblea General del poblado de Aguacatenango, Municipio de Venustiano Carranza, Estado de Chiapas, con fecha 5 de mayo de 2012 acordó presentar por la vía de jurisdicción voluntaria la solicitud de reconocimiento y titulación de esas tierras mancomunadas, ya que las habían mantenido en posesión de manera pacífica y continua por más de 500 años.

\section{JUSTICIABILIDAD: EJECUCIÓN DE LA SENTENCIA DE JURISDICCIÓN VOLUNTARIA (2012-2017)}

Como lo hemos apuntado, la Constitución Política de los Estados Unidos Mexicanos de 1917 es mundialmente reconocida como la primera en su tipo por reconocer y proteger derechos sociales como el derecho a la propiedad social y al trabajo, posteriormente, con el devenir del tiempo se agregarían otros como el de la seguridad social, la educación, la alimentación, los derechos de indígenas y sus pueblos, y el derecho a un ambiente sano. Los derechos sociales a nivel internacional se conocen o denominan como DESC o Derechos Económicos, Sociales y Culturales. stos implican obligaciones para los Estados y su cumplimiento tiene que ver con el concepto de justiciabilidad.

Entendemos por justiciabilidad no solo la posibilidad de activar la intervención del Estado a través de su aparato de justicia - por un lado las procuradurías de justicia como parte del Poder Ejecutivo y, por otro, los jueces, magistrados y ministros del Poder Judicial-, sino también que las resoluciones que resultan de esa activación tengan realización inmediata y se materialicen en la mejora de las condiciones de vida de la gente (Emanuelli, 2014). Es decir, la Justiciabilidad es y existe si al activar los mecanismos de acceso a la justicia del Estado, éstos son realmente accesibles y eficaces para detener una trasgresión a los derechos, resarcir los daños, impedir la repetición de los actos violatorios, y, sobre todo, dar lugar a la Justicia Social que es justamente la que mejora las condiciones de vida de las personas.

Sentencia a favor de Aguacatenango

En la cronología presentada en apartados anteriores señalamos que en 2013 se presenta juicio de jurisdicción voluntaria por el poblado de Aguacatenango. Después de una serie de vicisitudes -como el hecho del cambio de domicilio del Tribunal Unitario Agrario de un municipio a otro y el hecho de que finalmente asistieron los representantes de los ejidos colindantes para expresar su aceptación de los límites entre sus tierras y las reclamadas por Aguacatenango, y ante la ausencia de los pequeños propietarios también colindantes, el Tribunal Unitario Agrario (TUA) resolvió en el año 2016 que se realizaran los trabajos técnicos necesarios para la delimitación y deslinde de las tierras reclamadas. El proceso en este punto se detiene porque el TUA argumenta no contar con perito topógrafo para realizar ese trabajo ni con el dinero para contratarlo, por lo que pide al pueblo de Aguacatenango señalar al profesionista que lo haga, y por tanto pagar los gastos y emolumentos. Esto se da a pesar de que en todo momento la comunidad expresó no contar con ingresos suficientes para hacerlo, como se expuso en la última audiencia.

Tenemos entonces la resolución de un juez a favor del pueblo, en un sentido estricto de justiciabilidad. Pero como lo hemos definido y argumentado, no hay tal justiciabilidad porque, aunque discursivamente es favorable esa resolución, deja en las mismas condiciones, o aun peor al pueblo de Aguacatenango y a sus representantes, dados los gastos que se hubieron de realizar y las expectativas sembradas en la población. 
Finalmente, el argumento que el poblado esgrimió ante el Tribunal Superior Agrario (TSA con sede en la Ciudad de México) a través del recurso denominado excitativa de justicia fue justamente la injusticiabilidad de la resolución favorable, porque queda inconclusa. Ante esto el TSA otorga la razón a Aguacatenango y ordena al TUA ejecutar su propia sentencia, es decir, contratar los servicios de un topógrafo o profesionista que lo haga.

\section{REFLEXIONES FINALES}

Como lo señalamos al principio de este trabajo, sin lugar a dudas el caso expuesto pone en entredicho la efectividad del reconocimiento de los derechos de los pueblos indígenas y la justiciabilidad de los derechos de los pobladores indígenas como sujetos agrarios en el marco de la Ley Agraria de 1992.

Es importante apuntar que los procedimientos de las acciones agrarias en el Derecho Agrario anterior al año 1992 eran dilatados. Es decir, entre el inicio de una acción agraria, la resolución presidencial y finalmente su ejecución pasaban por lo menos periodos de 5 a 10 años por etapa hasta satisfacer el reclamo de dotación de tierra o de reconocimiento de posesión.

Dado que el reparto agrario fue cancelado en 1992, las acciones agrarias ya no existen porque "ya no hay tierra que repartir", pero muchas acciones agrarias de solicitud de tierras iniciadas antes de 1992 quedaron pendientes de resolución.

Por todo ello, uno de los propósitos de la modificación del marco jurídico agrario en 1992 era establecer una justicia expedita a través de un órgano independiente del Poder Ejecutivo. En efecto, antes de 1992 la justicia agraria se impartía por órganos que se encontraban dentro de lo que era la Secretaría de la Reforma Agraria (SRA) -ahora Secretaria de Desarrollo Agrario, Territorial y Urbano (SEDATU)-, la cual ya no tiene esa atribución. Ahora los Tribunales Agrarios se encargan de esto pero, como se ha expuesto, tal justicia no ha sido tan expedita.

Lo anterior pone en estado de inseguridad a cualquier comunidad y pueblo, sea indígena o no, ya que los mismos basan sus modos de vida y subsistencia en la tierra y el territorio.

Si bien en el procedimiento que expusimos, ante el Tribunal Unitario Agrario se respetaron tanto el derecho de la comunidad a contar con un intérprete traductor, así como su condición de pueblo indígena con derecho a reclamar la propiedad colectiva y social de la tierra dada por su posesión ancestral, esto resulta insuficiente porque los plazos de resolución definitiva -como en el caso de Aguacatenango- no se han acotado, hecho que pone en riesgo derechos colectivos fundamentales como la tierra y el territorio, y, en última instancia, su subsistencia y pervivencia como pueblo indígena. Recordemos en este sentido que mientras se tramita la titulación de las tierras del asentamiento humano existe la demanda del personaje que prometió que a Aguacatenango le regresarían su categoría de municipio, y lo que pide ese personaje es que le regresen el inmueble que el pueblo le permitió ocupar, sobre el que él arguye que se trata de su domicilio. Esto es a lo que configura lo que denominamos amenaza de despojo.

\section{REFERENCIAS}

Bárcena, A. E. (2017). Antropología del derecho: notas sobre sus aportes para la justiciabilidad de los derechos indígenas. Redhes. Revista de Derechos Humanos y Estudios Sociales, IX(17), 61-80. Recuperado de: https://www. researchgate.net/publication/318642721_ANTROPOLOGIA_DEL_DERECHO_NOTAS_SOBRE_SUS APORTES

PARA_LA_JUSTICIABILIDAD_DE_LOS_DERECHOS_INDIGENAS_LEGAL_ANTHROPOLOGY_NOTES_OI

Bellinghausen, H. (2008). El gobierno de la entidad concesionó espacios en 29 municipios. Comprende unas 550 mil hectáreas el plan minero canadiense en Chiapas, La Jornada Politica, 24(8581) Recuperado de: http://www.jo rnada.unam.mx/2008/07/08/index.php?article=010n2pol@ion=politica 
Brugger, S. I. (2008). La tecnocracia en México. Reflexiones sobre la economia mexicana. s/n Recuperado de: http://ec onomiamx.blogspot.mx/2008/05/la-tecnocracia-en-mxico.html

Burguete, C. A., \& A. McKelvey. (2013). Constitutional Multiculturalism in Chiapas. Hollow Reforms that Nullify Autonomy Rights. En T. Eisenstadt (ed.), Latin America's Multicultural Movements and the Struggle between Communitarianism, Autonomy, and Human Rights (pp. 40-67). New York: Oxford University Press

Carmona, D. D. (2017). Inicia el proceso de Nacionalización de la industria eléctrica. Memoria política, s/n Recuperado de: http://memoriapoliticademexico.org/Efemerides/9/27091960.html

Cruz, R. E. (2013). Capítulo 9. Derecho a la tierra y el territorio: demandas indígenas, Estado y capital en el Istmo de Tehuantepec. En C. M. T. Sierra, R. A. Hernández y R. Sieder (eds.), Justicia indígena y estado. Violencias contemporáneas (pp. 341-382). Ciudad de México: FLACSO-CIESAS.

Cruz, R. E. (2011). Eólicos e inversión privada. El caso de San Mateo del Mar, en el Istmo de Tehuantepec Oaxaca. Journal of Latin American Anthropology, 16(2), 257-277.

Emanuelli, M. S. (2014). La justiciabilidad de los DESC en México: retos y avances. En M. C. Alcayde, M. S. Emanuelli, T. Gómez, A. S. Omar y Terán ¿Hay justicia para los Derechos Económicos, Sociales y Culturales? Debate abierto a propósito de la reforma constitucional en materia de derechos humanos (pp. 107-127). Ciudad de México: Suprema Corte de Justicia de la Nación. Universidad Nacional Autónoma de México-Instituto de Investigaciones Jurídicas.

García, B. J. (1982). El precerámico de Aguacatenango. Chiapas. México. Instituto Nacional de Antropología e Historia. Prehistoria Colección Cientifica, 110, p.86

Gómez de Silva, C J. J. (2016). El derecho agrario mexicano y la Constitución de 1917. Instituto Nacional de Estudios Históricos de las Revoluciones de México. Ciudad de México: Secretaria de Gobernación. Instituto de Investigaciones Jurídicas/Universidad Nacional Autónoma de México. México Instituto Nacional de Estadística Geografía e Informática INEGI (2018). Archivo Histórico de Localidades Geoestadísticas. Recuperado de: htt p://geoweb2.inegi.org.mx/ahl/realizaBusquedaurl.do

Perezgrovas, G. R. (2007). Cría de cerdos autóctonos en comunidades indígenas. San Cristóbal de las Casas: Universidad Autónoma de Chiapas. Instituto de Estudios Indígenas.

Registro Agrario Nacional. Padrón e Historial de Núcleos Agrarios PHINA (2017). Recuperado de: http://www.ra n.gob.mx/ran/index.php/sistemas-de-consulta/phina

Medina C. J. R. (1987). Derecho Agrario. Ciudad de México: Harla.

Valladares de la Cruz, Laura (2008). La política de la multiculturalidad en México y sus impactos en la movilización Indígena: avances y desafíos en el nuevo milenio. En F. García (coord.), Identidades, etnicidad y racismo en América Latina,(pp. 289-308). Ecuador: FLACSO.

\section{Notas}

1 La Constitución mexicana tiene 136 artículos, por lo que las modificaciones superan en número su contenido actual.

2 En otras palabras, las nacionalizaciones de las industrias del petróleo en 1938 y de electricidad 1960 han sido prácticamente desmanteladas, ya que desde el sexenio de Carlos Salinas de Gortari fueron reformándose las leyes secundarias (que reglamentan lo señalado en los artículos de la Constitución Federal) para dar paso a la reprivatización de ambas industrias como parte de los bienes nacionales y que marcaría la era del neoliberalismo en nuestro país. Proceso que se concretaría empezando con la llamada contrarreforma agraria (en el año 1992), para sentar los cimientos de las contrarreformas energéticas que serían diseñadas inmediatamente después de esos dos sexenios (con Vicente Fox 2000-2006 y Felipe Calderón 2006-2012), y con mayor ímpetu al arribo en 2013 en pleno periodo presidencial de Enrique Peña Nieto (2012-2018). Para mayor detalle del proceso de reforma constitucional en estos periodos y aprovechando el centenario de la Constitución Política de los Estados Unidos Mexicanos de 1917, consultar: http:// constitucion1917.gob.mx/es/Constitucion1917/Reformas_a_la_Constitucion_de_1917 (recuperado el 18 de febrero de 2017)

3 La reforma a la Ley de Expropiación se dio en el periodo de Felipe Calderón, y justamente se agrega el término de ocupación temporal. 
4 Para Samuel I. B. (2008) “...El principal interés de los políticos mexicanos era instrumentar políticas que complacieran a los principales actores políticos de la arena nacional, mientras que los tecnócratas eran independientes, no tenían las presiones políticas y por consiguiente sus decisiones se basaban en la teoría económica. (...) olvidarse totalmente de las reglas democráticas, olvidándose tanto del pueblo como de los principales actores políticos (...)”. De esta manera, aunque el concepto de tecnócrata y tecnocracia se acuña desde los años sesenta del siglo pasado, en México tiene su máxima representación en el sexenio de Salinas de Gortari y Ernesto Zedillo, lo cual continuaría con Vicente Fox, que daría énfasis en la parte de impulso empresarial sin dejar la visión tecnócrata.

5 Tribunal Unitario Agrario 